Varun Mittal* and Shishir Sinha

\title{
Study the effect of fiber loading and alkali treatment on the mechanical and water absorption properties of wheat straw fiber-reinforced epoxy composites
}

DOI 10.1515/secm-2015-0441

Received October 26, 2015; accepted February 26, 2016; previously published online March 30, 2016

\begin{abstract}
The aim of this research was to study the feasibility of using wheat straw fiber with epoxy resin for developing natural fiber-polymer composites. For this purpose, the epoxy resin was reinforced with 5, 10, 15, 20 , and $25 \mathrm{wt} . \%$ of the wheat straw fiber with the help of the hand lay-up technique. Further, in order to improve the composite characteristic, wheat straw fibers were treated with three different concentrations of alkali (1\%, $3 \%$, and 5\%). The mechanical and water absorption properties of the treated fiber composites were characterized and compared with those of untreated fiber-filled epoxy composites. It was observed that the mechanical properties and water resistance were reduced with the increase in wheat straw fiber loading from 5 to $25 \mathrm{wt} . \%$. Among the three levels of alkali treatment, the composite made with 3\% alkali-treated fiber exhibited superior mechanical properties than the other untreated and treated fiber composites, which pointed to an efficient fiber-matrix adhesion. The scanning electron microscope was used to observe the surface features of the wheat straw fiber.
\end{abstract}

Keywords: composites; epoxy resin; mechanical properties; water absorption; wheat straw.

\section{Introduction}

The requirement for natural fiber composite products such as ply board, door panels, dashboards, etc., has been

*Corresponding author: Varun Mittal, Department of Chemical Engineering, Indian Institute of Technology Roorkee, Roorkee 247667, Uttrakhand, India, Tel.: +91-9897154061, e-mail:vrn.mttl1@gmail.com

Shishir Sinha: Department of Chemical Engineering, Indian Institute of Technology Roorkee, Roorkee 247667, Uttrakhand, India increasing worldwide in recent years $[1,2]$. Owing to the low cost, low density, and effective mechanical properties of various natural fibers such as jute, bagasse, wheat straw, rice straw, coir, and banana, it is possible to use them as replacements for synthetic fibers in a composite application [3]. Various industries like packaging, automotive, and building construction have been encouraged to use biofibers in their applications in lieu of non-renewable reinforcing materials [4-6]. The chemical composition of wheat straw is similar to that of wood and cellulose structures, which are embedded in an amorphous matrix of hemicellulose and lignin. They have good mechanical strength. Various investigations have been carried out on several types of biofibers such as coir, wheat straw, banana, hemp, bamboo, and wood to study the influence of these fibers on the mechanical and thermal properties of composite materials. Some investigations have been carried out on wheat straw fiber (WSF) to study the effect of fiber on the mechanical and physical properties of composite materials.

For instance, Avella et al. examined the thermal and mechanical properties of wheat straw-reinforced polyester composites. Initially, WSF is treated with high-temperature steam, which provides the fiber a more reactive property and more cellulose content. The authors reported that the treated fiber composite has a higher value of the Young modulus than the neat polyester. From their thermal study, they found that the presence of WSFs in the composite increases the rate of polyester crystallization; this is due to the nucleating effect, while the crystalline of samples remains unchanged [7]. Xiaoqun et al. analyzed the various properties of medium-density wheat straw particle board using different adhesives like methylene diphenyl diisocyanate, urea formaldehyde, soybean protein isolate, and soybean flour as well as chemical treatment of the wheat straw. They reported that among all adhesives, the particle board made from methylene diphenyl diisocyanate showed the best mechanical performance and water resistance than the other adhesives. The treated wheat straw particle board had improved 
mechanical performance over the untreated wheat straw particle board [8]. Panthapulakkal and Sain studied the effect of molding techniques, compatibilizer, and fungal treatment of wheat straw and corn stem on the mechanical properties of the wheat straw/corn stem composites. They reported that higher shear compounding of WSF composites showed similar properties to that composite produced by the milled wheat straw. This is because fiber breakage is occurring during high shear compounding, which effects the similar aspect ratio to that of milled straw. Compatibilizer and fungal treatment also enhanced the tensile and flexural properties of the wheat straw polypropylene composites [9]. Halvarssona et al. studied the mechanical and water absorption properties of medium-density fiber board composites that are produced by various varieties of wheat straw and different resin contents (14-17\%) like urea melamine formaldehyde, a mixture of urea melamine formaldehyde-resin, and urea melamine phenol formaldehyde. They observed that the average density is the factor that affects properties like internal bond, modulus of rupture, and modulus of elasticity. The water absorption and material swelling properties of composites decrease or increase the density of straw. They also reported that increasing the melamine content in composites results in improvement in the water resistance and tensile properties [10]. Pan et al. examined the influence of WSF content, size, and coupling agent on the mechanical characteristics of WSF-reinforced polypropylene composites. They observed that increasing the WSF content up to $40 \%$ gives a better value of tensile strength and modulus but a lower value of elongation. They also found that composites made by fine particle fibers ( $>35$ mesh) have a little bit high value of tensile strength. They reported that composites attained a maximum value of mechanical strength at $10 \mathrm{wt} . \%$ maleic anhydride grafted polypropylene (MAPP) concentration, but the magnitude of the flexural modulus remained the same [11]. Reddy et al. examined the influence of fiber content and coupling agent (maleic anhydride grafted polypropylene) on the water absorption and flexural properties of WSF-reinforced clay composites. They reported that flexural modulus and resistance to water absorption improved by raising the concentration of WSF and that of the coupling agent. From the scanning electron microscopy (SEM) morphology, they observed that addition of coupling agent increases the interfacial adhesion between the fibers and polymer matrix, thus affecting the flexural properties of composites [12]. Zhang et al. analyzed the mechanical, thermal, and water absorption behavior of the wheat straw reinforced with urea-formaldehyde adhesives composite. They observed that the particle board formed with WSF shows efficient mechanical strength; hence, it is a desirable material to make these types of board. From the X-ray photo-electron spectroscopy results, they found that urethane groups $(-\mathrm{NH}-\mathrm{C}=\mathrm{O})$ are joined with the wheat straw surface, which gives a positive effect on the strength and thermal stability of composites [13]. Montaño-Leyva et al. studied the influence of fiber size (fiber median diameter $\mathrm{d}_{50}=1.1 \mathrm{~mm}, 62 \mu \mathrm{m}$, and $8 \mu \mathrm{m}$ ) on the mechanical properties of the composites that were fabricated by successive grinding processes (cut milling, impact milling, and ball milling, respectively). They reported that tensile modulus and stress at break improved while strain at break was reduced by increasing the fiber content up to 11.1 vol.\%. They found that the hydrophobicity of fibers can be increased by successive grinding, and small fibers have a large specific area for bonding. Interfacial adhesion is better in the $d_{50}=(8 \mu \mathrm{m}>62 \mu \mathrm{m}>1.1 \mathrm{~mm})$ order, whereas the fiber elongation (which reflects the fiber aspect ratio) decreases in the order $d_{50}=(1.1 \mathrm{~mm}>62 \mu \mathrm{m}>8 \mu \mathrm{m})$ [14]. Babaei et al. analyzed the effect of (three levels of both azodicarbonamide and nanoclay) loading on the mechanical and foaming properties of wheat straw flour/highdensity polyethylene composites. They observed that the average cell size and cell density improved with the addition of azodicarbonamide, but the simultaneous addition of both azodicarbonamide and nanoclay reduced the cell size and improved the cell density. Mechanical resistance also went down with a decrease in the content of the azodicarbonamide, whereas increasing the content of nanoclay up to $2 \%$ enhanced the mechanical resistance. The water absorption and thickness swelling properties also increased with the addition of azodicarbonamide [15]. Consequently, in this experiment, the effect of fiber content on the mechanical and water absorption behavior of the WSF epoxy composites was analyzed. The outcome of integrating the three levels of alkaline treatment of WSF-epoxy composite is also reported.

\section{Materials and methods}

\subsection{Materials used}

\subsubsection{Wheat straw fiber}

(i) WSF has been procured from a local agricultural farm in Meerut, Uttar Pradesh (India). The moisture content of fiber was found to be $6-7 \%$. The length of WSF varied from 8 to $15 \mathrm{~mm}$, with an average length of $12 \mathrm{~mm}$. WSFs were washed with distilled water to remove undesirable adhered impurities, followed 
by drying in an oven at $72^{\circ} \mathrm{C}$ for $48 \mathrm{~h}$ to remove moisture.

(ii) Owing to their high strength, toughness, and resilience, the epoxy resin AW106 and the curing agent HV953IN were selected. When mixed, they give excellent resistance to chemical and moisture attack, with outstanding electrical insulating properties. The mixture has a density of $1.1 \mathrm{~g} / \mathrm{cm}^{3}$. These were procured from M/S Petro Araldite Pvt. Limited, Manali, Chennai, India.

(iii) Sodium hydroxide $(\mathrm{NaOH})$ was procured from $\mathrm{M} / \mathrm{S}$ Himedia Laboratories Pvt. Limited, Mumbai, India.

\subsection{Method used}

\subsubsection{Untreated fiber}

The WSF was rinsed with distilled water and dried in an oven. The dried fibers were assigned as untreated fibers.

\subsubsection{Alkali treatment of the WSF}

WSF was soaked with a concentration of $1 \%, 3 \%$, and $5 \%$ $\mathrm{NaOH}$ solution at ambient temperature for $2 \mathrm{~h}$ [16], then washed with distilled water to remove the $\mathrm{NaOH}$ solution binding to the WSF, and dried in an air oven for $48 \mathrm{~h}$ at the temperature of $72^{\circ} \mathrm{C}$ before making the composites.

\subsubsection{Preparation of composites}

For the preparation of the composites, the epoxy resin (AW106) and curing agent (HV953IN) were mixed (as per the recommendation of the manufacturer) followed by adding (5, 10, 15, 20 and 25 wt.\%) the untreated and 1\%, $3 \%$, and 5\% alkali-treated WSFs, and stirred in a mixer for $10-15 \mathrm{~min}$ at a rotational speed of $223.6 \mathrm{~g}$ to obtain a homogenous mixture. The mixture was poured into the mold having a size of $300 \times 300 \times 10 \mathrm{~mm}^{3}$ and was cured for $24 \mathrm{~h}$ at ambient temperature. All composite materials made for this research were manufactured using the hand lay-up technique [17]. In order to avoid the problem of sticking of composite material, the mold was coated with Teflon sheet, which may lead to the problem of bubble formation. To overcome such a problem, a roll-over sheet with a heavy roller was incorporated. Every composite cast was cured under a load of $25 \mathrm{~kg}$ for $24 \mathrm{~h}$ before it was removed from the mold.

\subsubsection{Testing of mechanical properties}

The tensile and flexural properties of the WSF-epoxy composites were evaluated with a 2716-002 Instron Model 5982 (Grove city, PA, USA). These properties were determined in accordance with the ASTM D3039 [18] and ASTM D790 [19] procedure, respectively, at a cross-head rate of $2 \mathrm{~mm} / \mathrm{min}$. The dimension for the specimen were as follows: tensile, $250 \mathrm{~mm}$ long and $25 \mathrm{~mm}$ wide; flexural, $100 \mathrm{~mm}$ long and $25 \mathrm{~mm}$ wide.

The impact strength was calculated using an impact testing machine, TINIUS OLSEN Model Impact 104 (Hoorsham, PA, USA), with a hammer weighing $4 \mathrm{~kg}$. It was determined using ASTM standard D256 [20]. The test specimen had a dimension of $63.5 \mathrm{~mm} \times 12.7 \mathrm{~mm}$. Three specimens were tested in each composite, and the average value of specimens was recorded. In all experiments, due care was taken to check the reproducibility of data.

\subsubsection{SEM morphology}

An SEM study was conducted using LEO 435 VP with the following specifications: acceleration voltage up to $30 \mathrm{kV}$, magnification range $(10 \times-300,000 \times)$, detection mode (secondary and backscattered electron), and use of printer and camera to record images. The test sample was mounted on the apparatus after fusing with silver gel and coating with gold to avoid electrical charging during the examination period.

\subsubsection{Water absorption test}

The effect of water absorption on the WSF-epoxy composites was calculated using ASTM D570 [21]. The test specimen had dimensions of $76.2 \mathrm{~mm}$ length and $25.4 \mathrm{~mm}$ width. The percentage of water absorption in the composite material was determined by the weight difference between the sample immersed in distilled water and dry sample, using the following equation

$$
\% \mathrm{M}=\frac{\mathrm{MF}-\mathrm{MI}}{\mathrm{MI}} \times 100 .
$$

\section{Results and discussion}

\subsection{Mechanical properties}

Figures 1-5 show the effect of the WSF loading (5, 10, 15, 20 , and 25 wt.\%) and three levels of concentration (1\%, 


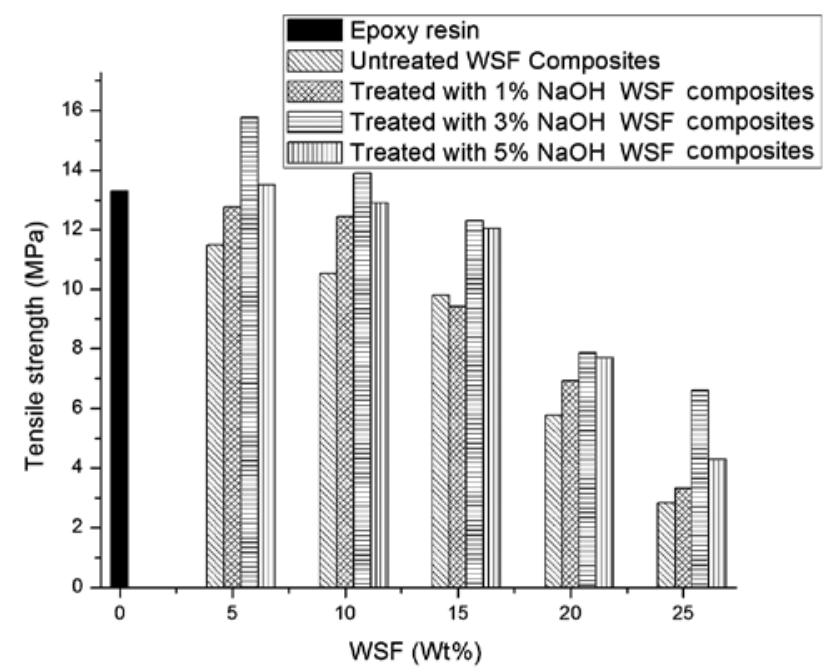

Figure 1: Effect of fiber content and alkali treatment on the tensile strength of WSF-epoxy composites.

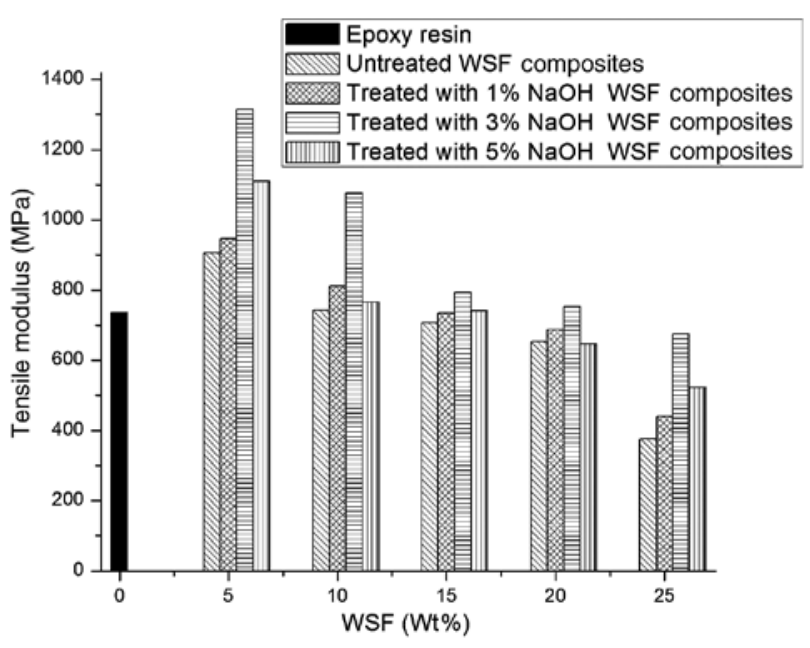

Figure 2: Effect of fiber content and alkali treatment on the tensile modulus of WSF-epoxy composites.

$3 \%$, and $5 \%$ ) of alkali treatment of fibers on the tensile strength, tensile modulus, flexural strength, flexural modulus, and impact strength of the WSF-epoxy composites. A reduction in the mechanical properties of WSFepoxy composites was observed with the addition of the WSF in neat epoxy resin. This is due to the low strength of the WSF and poor adhesion between the fiber and polymer matrix caused by a cluster of the fiber, resulting in the absence of polymer between the fibers.

As seen from Figures 1 and 2, the tensile strength and tensile modulus of the $1 \%$ alkali-treated fiber composites at $5 \%$ fiber loading were $12.8 \mathrm{MPa}$ and $945 \mathrm{MPa}$, respectively, against the tensile strength and tensile modulus of untreated fiber composites (11.5 MPa and $906 \mathrm{MPa}$, respectively).

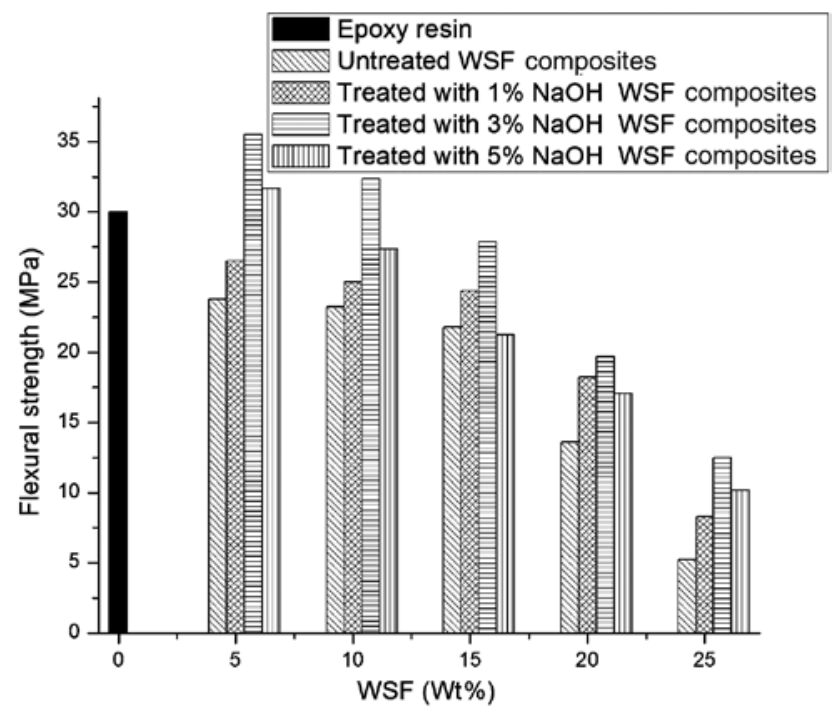

Figure 3: Effect of fiber content and alkali treatment on the flexural strength of WSF-epoxy composites.

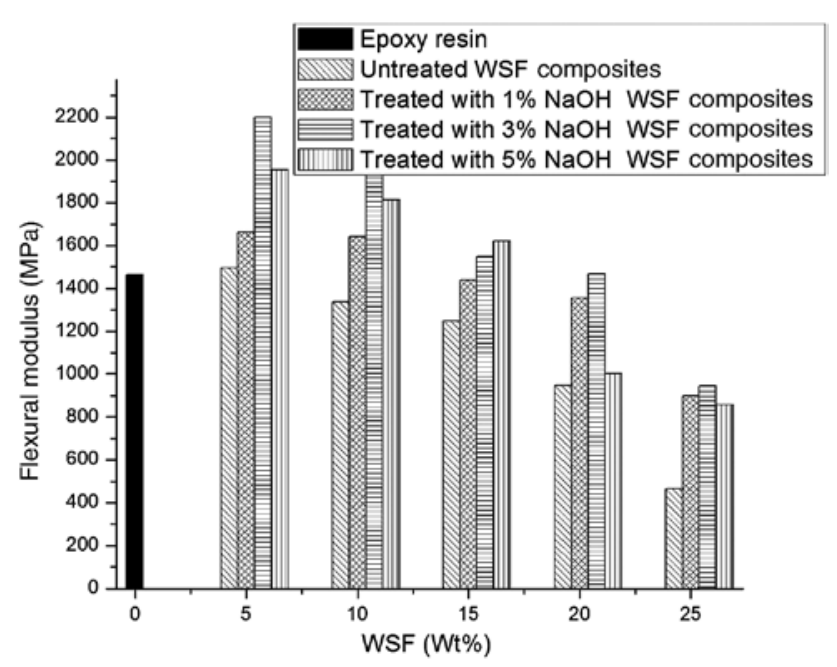

Figure 4: Effect of fiber content and alkali treatment on the flexural modulus of WSF-epoxy composites.

There was an improvement of approximately $11 \%$ in tensile strength and $4 \%$ in tensile modulus of the composite made with $1 \% \mathrm{NaOH}$-treated fibers. Further, with the $\mathrm{NaOH}$ concentration increased to $3 \%$, the tensile strength was changed from 12.8 to $15.8 \mathrm{MPa}$, and the tensile modulus was also increased from 945 to $1315 \mathrm{MPa}$. Finally, when the $\mathrm{NaOH}$ concentration was increased to $5 \%$, we observed that both tensile strength and tensile modulus decreased.

Similarly, from Figures 3 and 4, the flexural strength and flexural modulus of the $1 \%$ alkali-treated fiber composites at 5\% fiber content were $26.5 \mathrm{MPa}$ and $1663 \mathrm{MPa}$, respectively, against the flexural strength and flexural modulus of untreated fiber composites of $23.8 \mathrm{MPa}$ and 


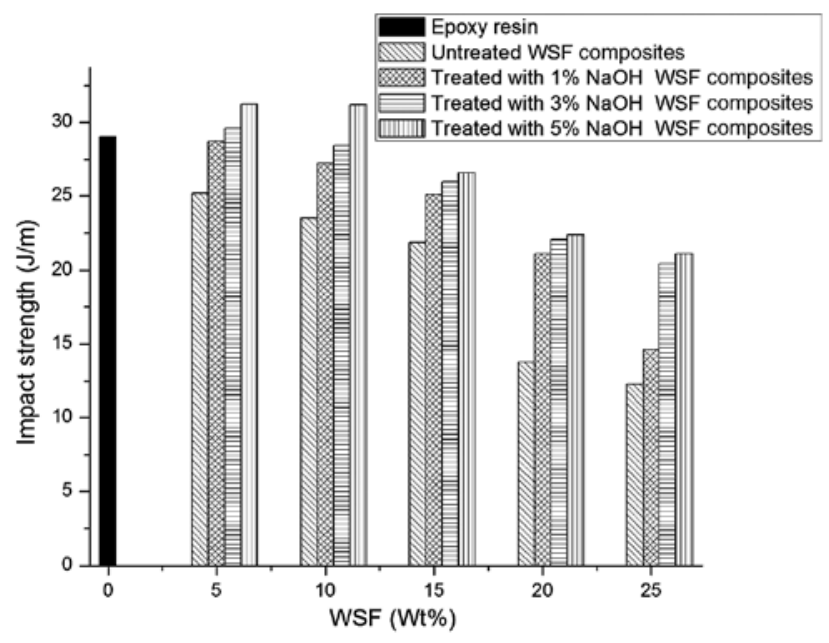

Figure 5: Effect of fiber content and alkali treatment on the impact strength of WSF-epoxy composites.
$1496 \mathrm{MPa}$, respectively. An improvement of approximately $11 \%$ was observed in both flexural strength and flexural modulus. Further, when the $\mathrm{NaOH}$ concentration increased to 3\%, the flexural strength increased from 26.5 to $35.5 \mathrm{MPa}$ and the flexural modulus also increased from 1663 to $2200 \mathrm{MPa}$. Lastly, when the $\mathrm{NaOH}$ concentration was increased to $5 \%$, we observed that both flexural strength and flexural modulus decreased.

From Figure 5, WSF-epoxy composites showed low impact strength compared to pure epoxy. The impact strength of neat epoxy was $28.8 \mathrm{~J} / \mathrm{m}$; after the addition of $5 \%$ untreated WSF in the polymer, the impact strength of the composites was reduced to $25.2 \mathrm{~J} / \mathrm{m}$. The impact strength of the $1 \%$ alkali-treated fiber composites remarkably increased from 25.2 to $28.7 \mathrm{~J} / \mathrm{m}$. Further, when the $\mathrm{NaOH}$ concentration was increased to $3 \%$, the impact
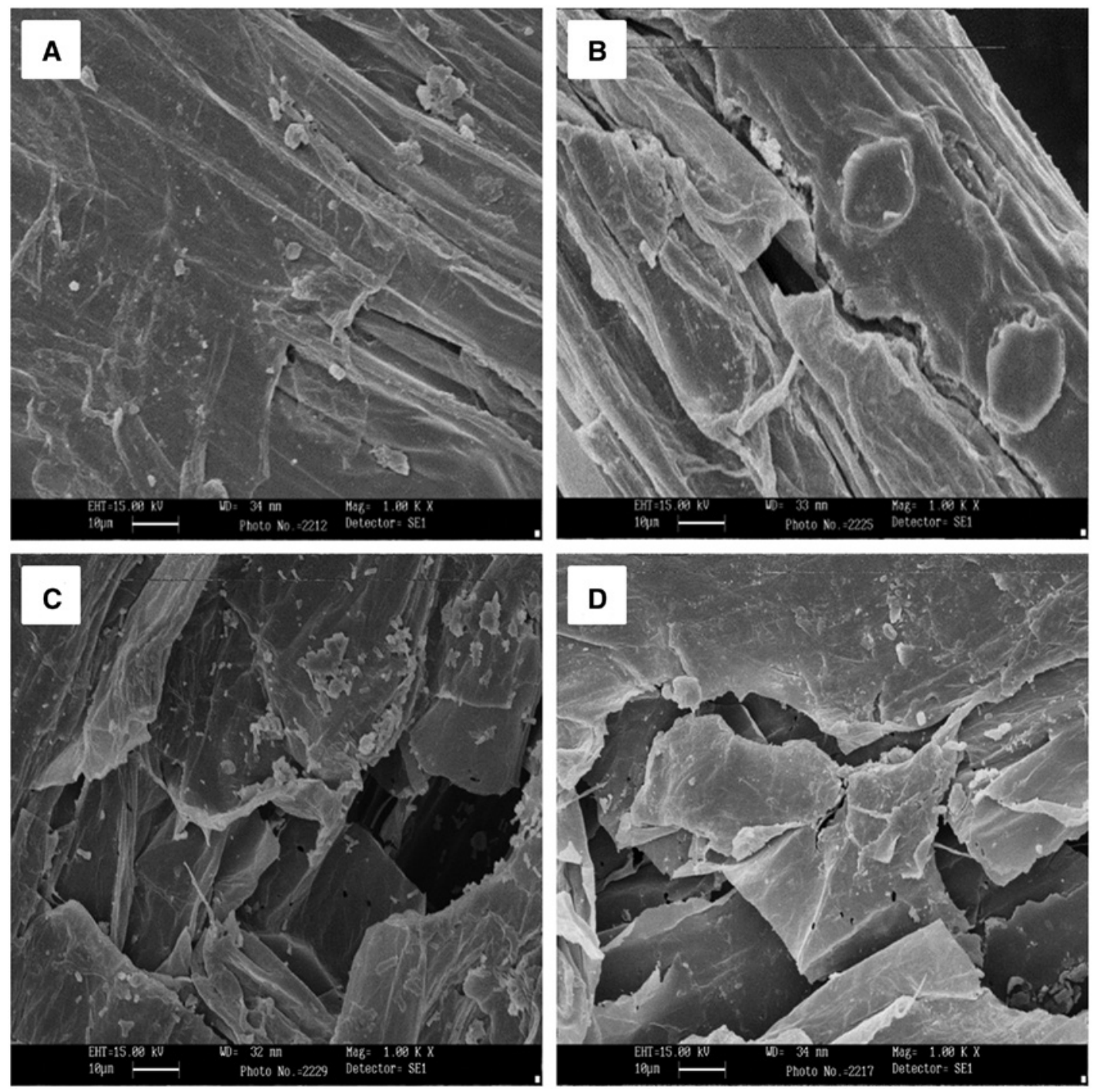

Figure 6: SEM morphology of wheat straw: (A) untreated, (B) treated with $1 \% \mathrm{NaOH},(\mathrm{C})$ treated with $3 \% \mathrm{NaOH}$, and (D) treated with $5 \% \mathrm{NaOH}$. 

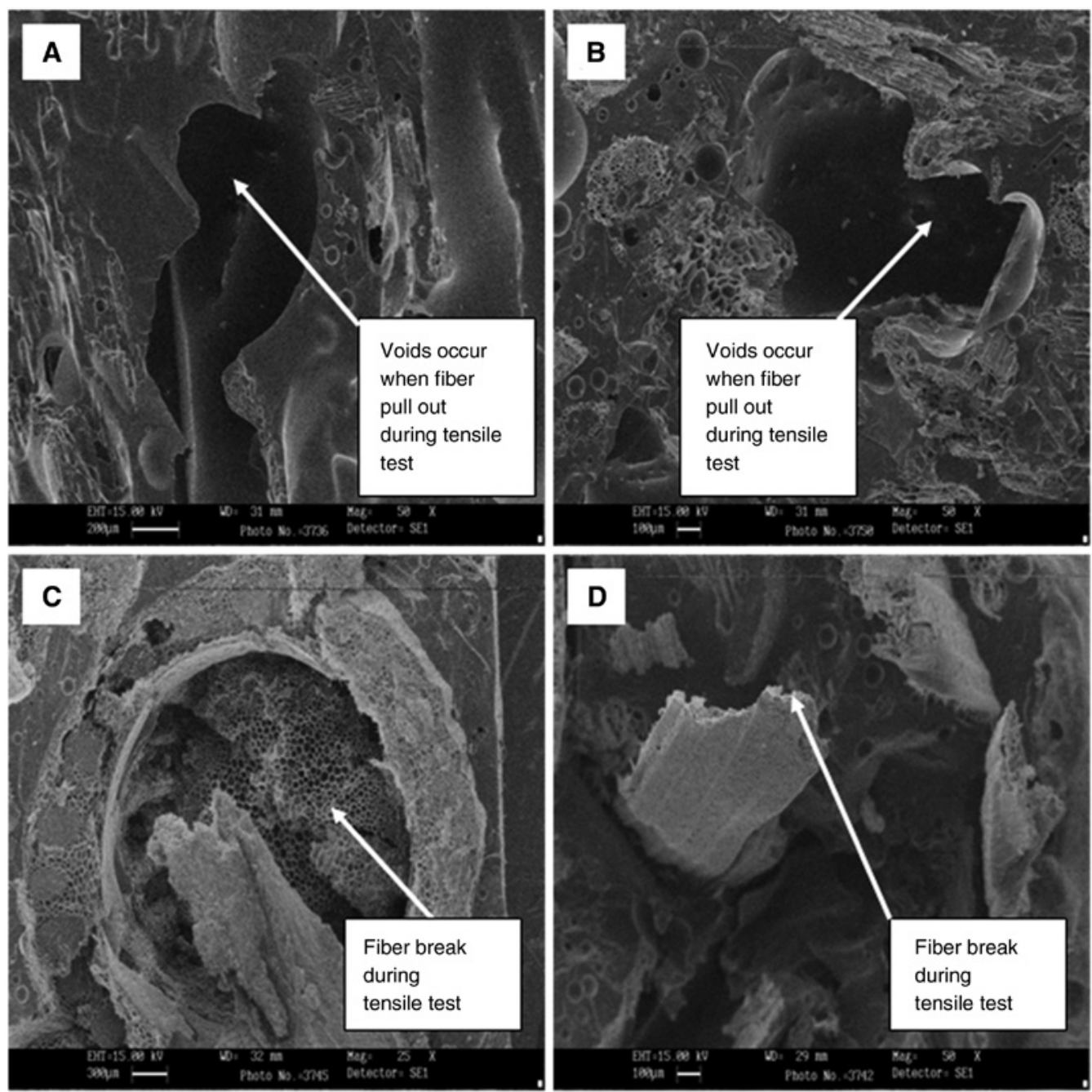

Figure 7: SEM morphology of tensile fractured surface of all composites: (A) untreated, (B) treated with $1 \% \mathrm{NaOH}$, (C) treated with $3 \% \mathrm{NaOH}$, and (D) treated with $5 \% \mathrm{NaOH}$.

strength also increased from 28.7 to $29.6 \mathrm{~J} / \mathrm{m}$. Finally, when the $\mathrm{NaOH}$ concentration was increased to $5 \%$, the impact strength increased to $31.2 \mathrm{~J} / \mathrm{m}$.

Similar results had been found in the case of coir-polyester composites [22]. As described above, the fibrillation provides a good interfacial adhesion between the fiber polymer matrix. However, for the $5 \% \mathrm{NaOH}$-treated fiber composites, the mechanical properties decreased with the greater fibrillation because the larger fiber at break led to stress losses at the interface of the polymer and fiber. The maximum improvement in tensile and flexural properties was observed in the 3\% NaOH-treated fiber composites; however, the impact strength had a high value in the 5\% $\mathrm{NaOH}$-treated fiber composites.

However, the effect of various levels of alkali treatment on WSF was observed to increase the above properties of the composites at all the WSF contents investigated. Wheat straw is a natural lignocellulose fiber. WSF is made up of crystalline cellulose that is surrounded by hemicellulose and lignin. These cells have a long end and are overlapping with each other, and form the cellular structure. The $\mathrm{NaOH}$ reacts with hydroxyl groups, which are available in the hemicellulose part of the fiber, which contributes to the death of the cellular part of the fiber and thereby the fibers are broken into various filament parts.

\subsection{SEM analysis}

The morphology of the fiber surfaces that were treated with alkali at different levels is shown in Figure 6A-D. It was observed that the filaments in the untreated fiber were joined together, but separated after the application of the alkali treatment. This process is termed as branching, which means breaking the untreated fiber into smaller scales by the dissipation of the hemicellulose 


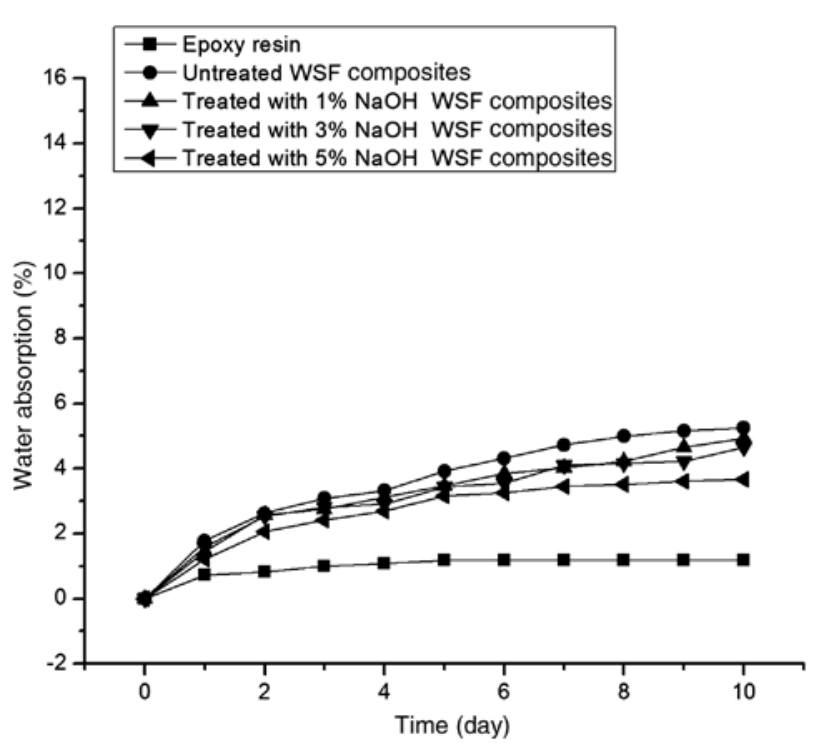

Figure 8: Water absorption curve for the WSF composites.

present in the fiber. The branching increases the adhesion surface area present between the fiber and polymer, leading to a strong bonding between them [23]. Hence, alkali treatment helps improve the interfacial adhesion. Figure 7A-D represents the morphology of the tensile fractured surface of untreated, $1 \%, 3 \%, 5 \%$ alkali treated fiber composites respectively [24].

\subsection{Water absorption}

Figure 8 shows the percentage intake of water absorbed in untreated and various levels of alkali-treated WSF-epoxy composites. It was observed that the natural fiber composites had higher water absorption than pure epoxy resin; with increases in the fiber content in epoxy, water absorption also increases because the lignocellulose materials absorb more water.

On the other hand, it was observed that the alkali treatment of WSF decreased the water absorption in the WSF composites, as shown in Figure 8; the $5 \% \mathrm{NaOH}$ treated WSF composite at the optimum point ( $5 \%$ WSF content) had 3.5\% absorbed water while the untreated WSF composite had 5\% absorbed water for 10 days. It has been proved that alkali treatment decreases the water absorption characteristic of composites.

\section{Conclusions}

Epoxy composites reinforced by untreated and 1\%, 3\%, and $5 \%$ alkali-treated WSFs were prepared. The tensile, flexural, and impact strength of the all WSF-epoxy composites decreased with the addition of fiber content in the polymer matrix. All alkali-treated WSF-epoxy composites exhibited better mechanical properties than the untreated WSF-epoxy composites having the same fiber loading. This is because their respective treatment constructed rougher surfaces, which provided a strong bonding between the fiber and polymer matrix. An efficient improvement in tensile strength and flexural strength was observed in composites prepared with the $3 \% \mathrm{NaOH}$-treated fiber, and in the impact strength of composites prepared with the $5 \% \mathrm{NaOH}$-treated fiber. These results were supported by SEM micrographs of the variously treated fiber surface, showing that the fibrils in the untreated fiber were coupled together but got split after the alkali treatment, offering more surface available for the adhesion between the fiber and polymer, increasing the strength of the composites.

\section{Nomenclature}

$\begin{array}{ll}\text { M } & \text { water absorption } \\ \text { MF } & \text { weight after immersion in water } \\ \text { MI } & \text { dry initial weight } \\ \text { NaOH } & \text { sodium hydroxide } \\ \text { SEM } & \text { scanning electron microscopy } \\ \text { WSF } & \text { wheat straw fiber }\end{array}$

Acknowledgments: Varun Mittal is extremely grateful to the Ministry of Human Resources and Development, New Delhi, for providing fellowship for this research work. The authors are also thankful to the Department of Chemical Engineering, Indian Institute of Technology Roorkee, for providing us with the necessary equipment and technical knowledge for the success of this research work.

\section{References}

[1] Zheng Y, Zhang RJ, Jenkins BM, Blunk S. Bioresour. Technol. 2007, 98, 1304-1310.

[2] Hervillard T, Cao Q, Laborie M. Bioresources 2007, 2, 148-156.

[3] Rong MZ, Zhang MQ, Lui Y, Yang G, Zeng HM. Compos. Sci. Technol. 2001, 61, 1437-1447.

[4] Bachtiar D, Sapuan SM, Hamdan MM. Mater Des. 2008, 29, 1285-1290.

[5] Kumar V, Tyagi L, Sinha S. Rev. Chem. Eng. 2011, 27, 253-264.

[6] Kumar V, Sinha S, Singh MS, Kanungo BK, Biswas P. Rev. Chem. Eng. 2010, 26, 41-53.

[7] Avella M, Rota GL, Martuscelli E, Raimo M. J. Mater. Sci. 2000, 35, 829-836.

[8] Xiaoqun M, Cheng E, Wang D, Susan SX. Ind. Crops Prod. 2003, 18, 47-53. 
[9] Panthapulakkal S, Sain M. J. Polym. Environ. 2006, 14, 265-272.

[10] Halvarssona S, Edlunda H, Norgrena M. Ind. Crops Prod. 2008, 28, 37-46.

[11] Pan M, Zhou D, Bousmina M, Zhang SY. J. Appl. Polym. Sci. 2009, 113, 1000-1007.

[12] Reddy CR, Sardashti AP, Simon LC. Compos. Sci. Technol. 2010, 70, 1674-1680.

[13] Zhang Y, Jiyou G, Haiyan T, Mingwei D, Libi Z, Weng X. Bioresources 2011, 6, 464-476.

[14] Montaño-Leyva B, da Silva GGD, Gastaldia E, Torres-Chávezc P, Gontarda N, Angellier-Coussya H. Ind. Crops Prod. 2013, 43, 545-555.

[15] Babaei I, Madanipour M, Farsi M, Farajpoor A. Compos. Pt B 2014, 56, 163-170.

[16] Cao Y, Shibata S, Fukumoto I. Compos. Pt A 2006, 37, 423-429.

[17] Mittal V, Sinha S, J. Polym. Eng. 2015, 35, 545-550.
[18] ASTM D3039: Association Standards, Testing Materials, Standard Test Method for Tensile Properties of Polymer Matrix Composite Materials.

[19] ASTM D790: Association Standards Testing Materials. Standard Test Methods for Flexural Properties of Unreinforced and Reinforced Plastics and Electrical Insulating Materials.

[20] ASTM D256: Association Standards Testing Materials. Standard Test Methods for Determining the Izod Pendulum Impact Resistance of Plastics.

[21] ASTM D570: Association Standards Testing Materials. Standard Test Method for Water Absorption of Plastics.

[22] Rout J, Misra M, Tripathy SS, Nayak SK, Mohanty AK. Compos. Sci. Technol. 2001, 61, 1303-1310.

[23] Bisanda ENT, Ansell MP. Compos. Sci. Technol. 1991, 41, 165-178.

[24] Ray D, Sarkar BK, Ranac AK, Rose NR. Compos. Pt A 2001, 32, 119-127. 